\title{
CHROMATOGRAPHIC ANALYSIS OF CAROTENOIDS AND ANTHOCYANINS IN SWEET CHERRY AUTUMN LEAVES USED IN ORNAMENTAL LANDSCAPES
}

\section{TABITA-TEODORA LISANDRU ${ }^{a}$, ANDREA BUNEA $^{\mathrm{b}}$, ADRIAN FÜSTÖS $^{\mathrm{a}}$, ADELINA DUMITRAȘ ${ }^{c}$, CLAUDIU-IOAN BUNEA ${ }^{a}$, VALENTIN SEBASTIAN DAN ${ }^{a}$, EMESE GÁL $^{d}$, VIOREL MITRE $^{a *}$}

\begin{abstract}
The pigments composition of sweet cherry leaves (Prunus avium L.) were identified for the first time under condition of Cluj-Napoca city. Five cherry tree varieties (Merchant, Early Red, Lapins, Burlat, Kordia) have been selected in autumn of 2016 in order to identify and quantify the major pigments in these types of leaves. Five carotenoids (lutein, $\beta$ carotene, zeaxanthin, cis- $\beta$-caroten, $\alpha$-carotene) and one major anthocyanin (cyanidin-3-glucoside) were found in cherry leaves. The main carotenoids identified in all cultivars were lutein $(340.55 \mu \mathrm{g} / \mathrm{g})$, followed by $\beta$-carotene $(147.06 \mu \mathrm{g} / \mathrm{g})$. Early Red cultivar had the highest content of cyanidin-3glucoside $(17.96 \mathrm{mg} / 100 \mathrm{~g})$, followed by Kordia variety $(11.46 \mathrm{mg} / 100 \mathrm{~g})$. Cyanidin-3-glucoside is responsible for red coloration of the leaves, meanwhile lutein, $\beta$-carotene, zeaxanthin, cis- $\beta$-carotene and $\alpha$-carotene are providing yellow to orange colours of the leaves. The coloration of sweet cherry leaves, given by the accumulation of anthocyanin and carotenoids in autumn, makes this species suitable for ornamental use in urban design.
\end{abstract}

Keywords: anthocyanin, carotenoids, HPLC

\footnotetext{
a Department of Horticulture and Landscape Architecture, University of Agricultural Sciences and Veterinary Medicine, Calea Mănăştur 3-5, 400372, Cluj-Napoca, Romania

b Department of Biochemistry, University of Agricultural Sciences and Veterinary Medicine, Calea Mănăştur 3-5, 400372, Cluj-Napoca, Romania

c Department of Forestry, University of Agricultural Sciences and Veterinary Medicine, Calea Mănăştur 3-5, 400372, Cluj-Napoca, Romania

d Babeş-Bolyai University, Faculty of Chemistry and Chemical Engineering, 11 Arany János str., RO-400028, Cluj-Napoca, Romania,

* Corresponding author: viorel.mitre@usamvcluj.ro
} 


\section{INTRODUCTION}

Recently, leaves colour change of the deciduous tree in autumn gained a lot of interest when this remarkable phenomenon was observed from an ecological perspective [1]. To explain the significance of autumnal colours of the leaves a few hypotheses appeared [2, 3, 4, 5] but even so the dominant explanation is based on plant physiology: autumn bright colours are the result of leaf senescence, while physiological functions of leaves are related to pigments [6,7]. What it was not discussed yet, is how this phenomenon can be used with ornamental purpose by integrating some species into urban design because of their beautiful autumnal colours of the leaves. The colour change of the leaves remodels every year the landscape into a spectacular mosaic of yellow, orange and red [8]. Nevertheless, there are some deciduous tree species which lose their leaves without changing their colour. Just $\sim 10 \%$ of the trees from temperate clime present red autumn colours while $\sim 15 \%$ of the trees present yellow leaves colour $[9,8]$. Originally from Caspian and Black Seas, and currently spread in all continents [10] sweet cherry (Prunus avium L.) is one of the tree species which is changing the colour of the leaves from green to bright colours of yellow and red in autumn, creating wondrous landscapes and having a great ornamental potential. The cause of leaves colour change of cherry tree in autumn months is due to the accumulation of anthocyanin and carotenoids in the leaves.

Anthocyanins belong to flavonoids (plant secondary metabolites) and are water-soluble pigments responsible for the attractive colours of flowers, fruits and leaves [11, 12]. They provide red, blue and purple colours and are important phenolic component in colour traits of ornamental species. Red leaves are an important element in ornamental landscape use [13] which adds warmth to the landscape. Plants with colourful foliage have been always appreciated in landscape design because of the beautiful perspectives created by their presence and because they allow you to alter mood or perception of the urban space (e.g. make small spaces seem larger; focus attention to a particular area).

Anthocyanins are not the only pigments answerable for autumn colours; carotenoids pigments are contributing also to the autumn bright colours. Carotenoids are the second major group of pigments which accumulates in the plastids of leaves and provide red, orange and yellow pigments [14, 15]. Unlike anthocyanin, carotenoids are synthesized all along growing season in order to enable or protect photosynthetic light capture [16].

The magnificent appearance of autumn senescence is the result of the degradation of the chlorophyll which allows the red and yellow hues of anthocyanins and carotenoids to be visible $[17,9]$. 
Sweet cherry tree (Prunus avium L.) may be considered an ornamental species not just because of the beautiful flowers that provide in spring time but also for autumnal colours of the leaves that creates brilliant landscapes at the end of the vegetation period. Fruit trees were used with ornamental purpose since ancient time but over time their usage had just one purpose: fruit production. Nowadays, beside their fruit production and fruit nutritional values, fruit trees have begun to be part of landscape design being recognized for their ornamental values. Fruit trees are planted every year in urban greenery while the existing fruit trees are groomed and nurtured [18]. They are used in landscape either for fruits, either for the shade provided by the crown of the trees [19]. The shape of the crown, the vibrant colours of the leaves integrates fruit trees in urban design alongside ornamental plants creating attractive perspectives in urban cities.

In this work, we chose five varieties of sweet cherry tree (Prunus avium L.) with the purpose to identify the pigments that provide autumnal colors of leaves species. The selected cultivars are usually used in intensive and super intensive orchards but the leaves color change make these varieties suitable for landscape design use. This study was inspired by the colourful landscapes given by the leaves appearance of the sweet cherry tree (Prunus avium L.) in autumn months.

\section{RESULTS AND DISSCUSION}

\section{Carotenoid composition in leaves}

Five carotenoids answerable for yellow-orange colour were separated from Prunus avium L. leaves cultivars and have been identified according to their chromatographic and spectroscopic properties (UV-VIS spectra).

The average values of major carotenoids show significant differences between all five cultivars. The sweet cherry cultivar with the highest level of carotenoids was 'Merchant' $(220.06 \mu \mathrm{g} / \mathrm{g})$ followed by 'Burlat' $(114.04 \mu \mathrm{g} / \mathrm{g})$ and 'Kordia' $(112.3 \mu \mathrm{g} / \mathrm{g})$. The accumulation of pigments in 'Early Red' and 'Lapins' varieties is about three times lower than 'Merchant'. HPLC chromatogram of 'Lapins' cultivar obtained from pigments leaf extracts shows five carotenoid peaks corresponding to the retention time and spectra absorption to lutein, zeaxanthin, $\alpha$-carotene, $\beta$-carotene and cis- $\beta$-carotene (Figure 1). 


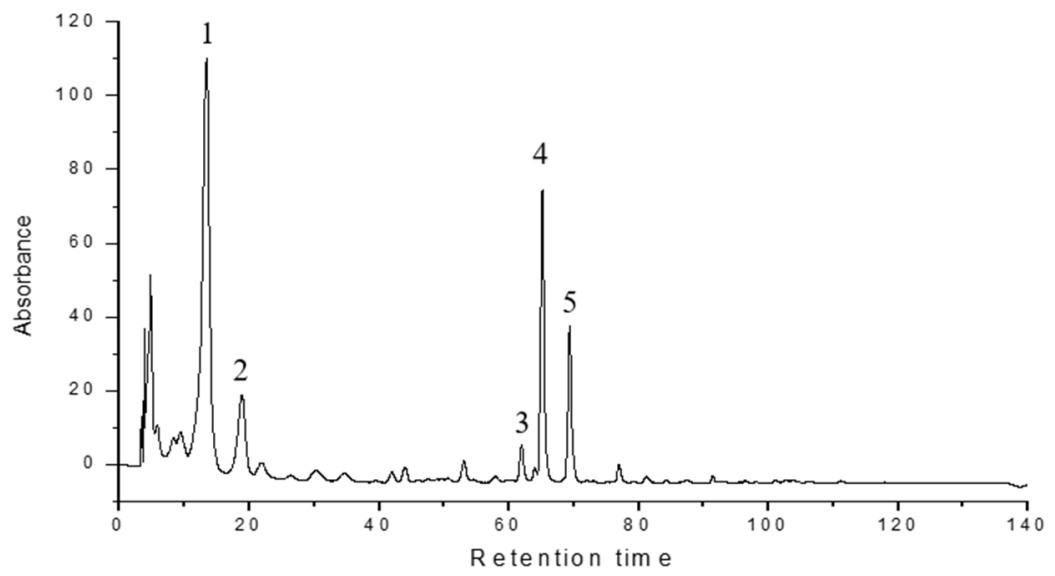

Figure 1. HPLC chromatogram obtained from carotenoid extracts from 'Lapins' cultivar leaves. 1 - Lutein; 2- Zeaxanthin, 3- $\alpha$-carotene; 4- $\beta$-carotene;

5 - cis- $\beta$-carotene

The main carotenoid found in all varieties of cherry leaves is represented by lutein, followed by $\beta$-carotene (Table 1). Previous studies results showed also lutein as major carotenoid in Moringa oleifera leaves, with a per cent of 53.6 and $52.0 \%$ of total carotenoids [20]. The content of lutein, for leaves of 'Burlat' variety was $87.84 \mu \mathrm{g} / \mathrm{g}$.

Table 1. Carotenoid composition $(\mu \mathrm{g} \pm \mathrm{SD} / \mathrm{g})$ of leaves of Prunus avium cultivars.

\begin{tabular}{|l|c|c|c|c|c|}
\hline \multirow{2}{*}{$\begin{array}{l}\text { Identified } \\
\text { carotenoids }\end{array}$} & \multicolumn{5}{|c|}{ Concentration of carotenoids $(\mu \mathrm{g} \pm \mathrm{SD} / \mathrm{g})$ in leaves } \\
\cline { 2 - 6 } & Merchant & Early Red & Lapins & Burlat & Kordia \\
\hline Lutein & $81.2 \pm 1.03^{\mathrm{b}}$ & $50.11 \pm 0.87^{\mathrm{d}}$ & $43.3 \pm 0.69^{\mathrm{e}}$ & $87.84 \pm 0.92^{\mathrm{a}}$ & $78.1 \pm 1.02^{\mathrm{c}}$ \\
\hline Zeaxanthin & $13.81 \pm 0.7^{\mathrm{a}}$ & $10.06 \pm 0.07^{\mathrm{b}}$ & $7.98 \pm 0.06^{\mathrm{c}}$ & $4 \pm 0.02^{\mathrm{e}}$ & $6.7 \pm 0.05^{\mathrm{d}}$ \\
\hline$\beta$-carotene & $87.9 \pm 1.65^{\mathrm{a}}$ & $7.28 \pm 0.02^{\mathrm{e}}$ & $14.43 \pm 0.2^{\mathrm{d}}$ & $17.55 \pm 0.2^{\mathrm{c}}$ & $19.9 \pm 0.5^{\mathrm{b}}$ \\
\hline cis- $\beta$-carotene & $37.15 \pm 0.9^{\mathrm{a}}$ & $3.34 \pm 0.02^{\mathrm{e}}$ & $8.07 \pm 0.06^{\mathrm{b}}$ & $4.65 \pm 0.08^{\mathrm{d}}$ & $7.63 \pm 0.06^{\mathrm{c}}$ \\
\hline $\begin{array}{l}\text { Total of } \\
\text { carotenoids }\end{array}$ & $220.06 \mathrm{~A}$ & $70.79 \mathrm{E}$ & $74.39 \mathrm{D}$ & $114.04 \mathrm{~B}$ & $112.33 \mathrm{C}$ \\
\hline
\end{tabular}

Different letters indicate statistical differences between Prunus avium varieties regarding the carotenoid composition in leaves ( $\mathrm{DS}_{5} \%=0.20-0.23$ ).

The statistical analysis from Table 1 was preformed between identified carotenoids from each cultivar. 
The leaves of 'Merchant' variety had a lutein content of $81.2 \mu \mathrm{g} / \mathrm{g}$, followed by 'Kordia' variety with lutein content of $78.1 \mu \mathrm{g} / \mathrm{g}$. Leaves of 'Early Red' and 'Lapins' varieties showed lutein content of $50.11 \mu \mathrm{g} / \mathrm{g}$ for 'Early Red' and $43.3 \mu \mathrm{g} / \mathrm{g}$ for 'Lapins'.

The results showed that there is a significant difference $(P<0.05)$ between levels of lutein content for these five cultivars of Prunus avium. The $\beta$-carotene levels found in cherry leaves also showed significant difference $(P<0.05)$ between all sweet cherry varieties.

'Merchant' leaves showed the highest level of $\beta$-carotene $(87.9 \mu \mathrm{g} / \mathrm{g})$, followed by 'Kordia' with a concentration of $19.9 \mu \mathrm{g} / \mathrm{g}$, 'Burlat' $(17.55 \mu \mathrm{g} / \mathrm{g})$, 'Lapins' $(14.43 \mu \mathrm{g} / \mathrm{g})$ and 'Early Red' $(7.28 \mu \mathrm{g} / \mathrm{g})$. Also, zeaxanthin and cis$\beta$-carotene were found in leaves of cherry tree. The levels of these two carotenoids showed significant differences between all cultivars studied $(P<$ $0.05)$. Another identified carotenoid was $\alpha$-carotene which was found just in leaves of 'Lapins' variety with a concentration of $0.61 \mu \mathrm{g} / \mathrm{g}$.

Pigments differences between Prunus avium cultivars have been interpreted by using principal component analysis (PCA). PCA multivariate statistical analysis shows the pigments concentrations differences between all five varieties of Prunus avium, with a sample variance of $99.9 \%$ defined by the first two components. Multivariate analysis shows a clear and significant separation of the 'Merchant' variety (from quadrant I) to the 'Early Red' cultivar and to the other thee cultivars similar to each other (Figure 2). The carotenoid pigment responsible for the difference is lutein.

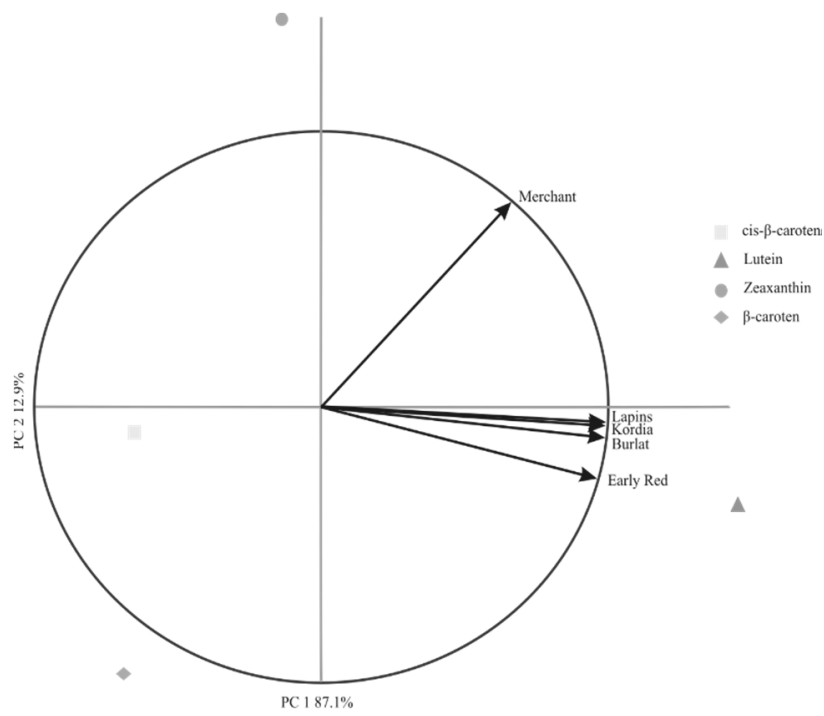

Figure 2. Principal component analysis. Correlation biplot $99.9 \%$ 
The results confirm the presence of five major carotenoid pigments in the leaves of cherry studied cultivars. The concentration of identified pigments is significantly different for each cultivar and all five varieties contained the same pigments, except 'Lapins' cultivar which contain also a small concentration of $\alpha$-carotene.

Anthocyanin composition in leaves. The anthocyanin pigments responsible for red and blue colour of plants were found in the leaves of Prunus avium studied cultivars. HPLC analysis showed one major anthocyanin peak, corresponding to the retention time and spectra absorption to cyanidin3-glucoside (Figure 3).

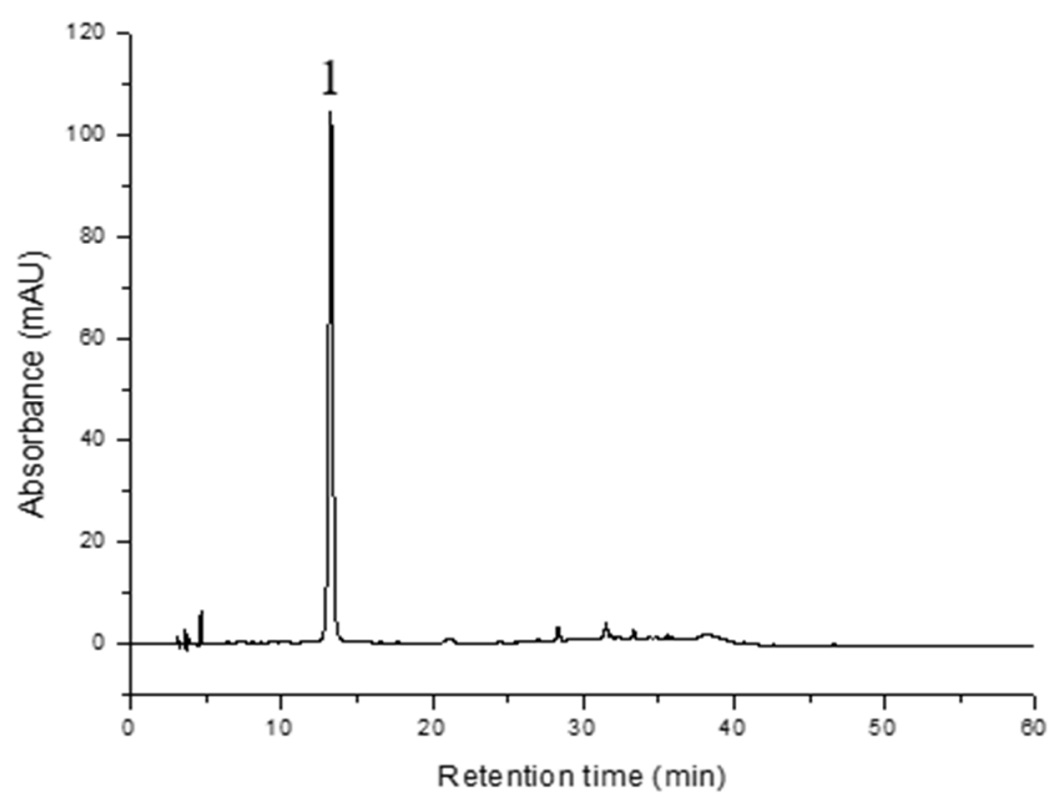

Figure 3. HPLC chromatogram obtained from anthocyanin extracts from 'Kordia' variety ( $P$. avium L.) leaves. Only one peak (1) was detected corresponding to cyanidin-3-glucoside

'Early Red' cultivar had the highest level of cyanidin-3-glucoside (17.96 mg/100g), followed by 'Kordia' (11.46 mg/100g), while 'Burlat' and 'Kordia' had similar content of anthocyanin pigment (Table 2). 
Table 2. The concentration of cyanidin-3-glucoside in sweet cherry leaves.

\begin{tabular}{|l|c|c|c|}
\hline Sweet cherry varieties & Cyanidin-3-glucoside (mg/100g) & $\pm d$ & $\begin{array}{c}\text { Mean } \\
\text { difference }\end{array}$ \\
\hline Merchant (Mt) & $9.85 \pm 1.23$ & 0.00 & - \\
\hline Kordia & $11.46 \pm 2.68$ & -1.61 & - \\
\hline Early Red & $17.96 \pm 3.24$ & -8.11 & ${ }^{* * *}$ \\
\hline Lapins & $5.77 \pm 0.78$ & 4.08 & ${ }^{* *}$ \\
\hline Burlat & $5.71 \pm 0.67$ & 4.14 & ${ }^{* *}$ \\
\hline
\end{tabular}

Different symbols indicate statistical difference between Prunus avium L. cultivars $\left(\mathrm{DL}_{5 \%}=2.2 ; \mathrm{DL}_{1 \%}=3.2 ; \mathrm{DL}_{0.1 \%}=4.81\right)$

The results of HPLC analysis showed that there was a significant difference ( $d \geq D L 0.1 \%$ ) between sweet cherry cultivars regarding the leaves content in cyanidin-3-glucoside. Although, 'Lapins' and 'Burlat' showed a similar concentration of anthocyanin pigments, which means that there is not a significant difference between these two cultivars.

Following the results, we observed that the anthocyanin composition of cherry leaves is generally inversely proportional to carotenoid content (Figure 4), which means that the ornamental value of this species in fall season is mostly given by carotenoids pigments. Yellow-orange pigments of cherry leaves are predominant and became visible earlier that anthocyanin pigments, but together they make this species suitable for landscape design use by giving it a great ornamental potential.

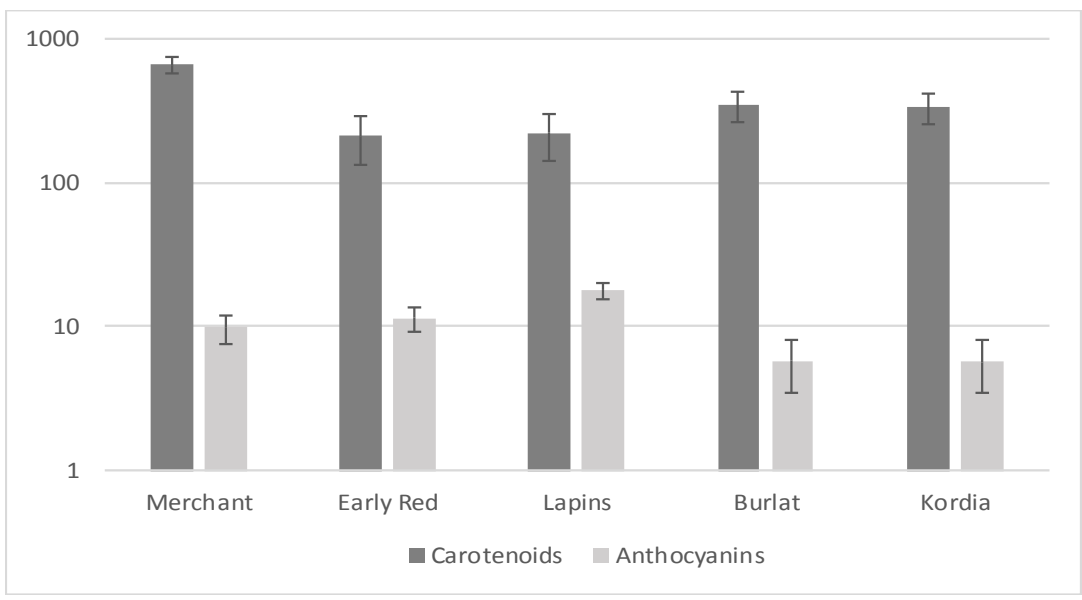

Figure 4. Differences among carotenoids and anthocyanin content in Prunus avium L. cultivars leaves 
The researches regarding the carotenoids and anthocyanin content in leaves of some sweet cherry cultivars has not been reported before, preceding studies been focused more on flowers, antioxidant efficiency and fruits quality of cherry tree. B.J. Glover consider that the research regarding plant leaves colour are limited recorded due to slight colour variation in comparison with flower colour [21].

In this research, the HPLC-PDA method was used to determine the pigments of cherry leaves and to establish the ornamental value of cherry tree given by leaves colour in autumn. Five carotenoids (lutein, $\beta$-carotene, zeaxanthin, cis- $\beta$-carotene, $\alpha$-carotene) and one anthocyanin (cyanidin-3glucoside) were found in composition of cherry leaves.

The red colour of the sweet cherry varieties leaves is provided by the presence of the anthocyanin pigments. Anthocyanin pigments are the most abundant polyphenols which can be found in all parts of the plant being responsible for red, violet and blue colours [22]. The coloration of the leaves in most species is the result of the accumulation of anthocyanin pigments in the vacuoles of (sub)epidermal cells, principally in flower, fruits and vegetables but also in leaves $[23,24]$. The colour of anthocyanin may change because of the acidity of the vacuole providing red colour in acidic environment and blue colour in neutral or weak acidic conditions [25].

Along sweet cherry leaves, in available literature there were reported different leaves species and cultivars which contained cyanidin-3-glucoside as major anthocyanin. For instance, the existence of cyanidin-3-glucoside pigment was showed in grape leaves in proportion of $43 \%$ [26]. Different sweet potato varieties leave had also a high content of cyanidin pigment indicating that the anthocyanin leaves composition may be cyaniding type [27]. Studies on crab-apple determined that cyanidin pigment was also the major anthocyanin, which was responsible for the various red colours of the leaves species [23]. The anthocyanin content of purple basil leaves was expressed as cyanidin-3-glucoside also [11].

The yellow-to-red colour of the leaves is provided by the accumulation of lipid-soluble compounds, carotenoids, in chloroplasts [28]. Carotenoids can be found as crystals, lipid-dissolved or lipid-crystalline forms in the chromoplast structure [29]. They protect the photosynthetic apparatus and appear as a result of leaf senescence in autumn, when chlorophyll is degraded and grants carotenoids to be visible [30,9].

Studies regarding the content of carotenoids in leaves were made before and there were reported similar content of $\beta$-carotene in leaves of Pereskia species (13.8-47.0 $\mu \mathrm{g} / \mathrm{g}$ ) as in 'Lapins', 'Burlat' and 'Kordia' cultivars [31]. Also, zeaxanthin levels found in cherry leaves were much higher than zeaxanthin values reported in spinach, endive or lettuce leaves (0.1-0.07 $\mu \mathrm{g} / \mathrm{g})[32]$. 
The existence of pigments in different species leaves was recorded during the time and it was the object of many studies in last decade. The colours change of the leaves of the species during the autumn months has triggered curiosity of scientists and ecologists which understood the importance of autumn phenology [33].

The autumnal landscapes have various intensity in every part of the world and bring millions of visitors to admire the spectacular perspectives created by the colourful leaves of the species [4], [34]. According to [35] and [36] red autumn leaves are dominating in some parts of the world like North America and East Asia, while yellow autumn leaves are dominating in Finland and temperate Northern Europe [37]. Anthocyanins and carotenoids pigments are repeatedly present in the same organs increasing in this way the colour variety and in the same time the ornamental value of the species [22].

On the other hand, colours are an important element in natural scenes that contributes to the visual recognition of the landscape [38], but also is a challenging subject to be studied [39]. Old literature and even modern one have not described properly the landscape importance of the colours of the leaves $[40,41]$ and [42] consider that the most problematic interpretation of visual world is colour [43].

\section{CONCLUSIONS}

The starting point of this study was to determine for the first time the anthocyanins and carotenoids from some sweet cherry cultivars (Prunus avium $\mathrm{L}$.) leave composition in order to identify the pigments which transform the leaves into a mosaic of colours in autumn months. Our results showed that cyanidin and carotenoids pigments are present in leaves composition of sweet cherry tree. According to these results and with the fact that anthocyanins and carotenoids are responsible for the autumnal colour of the leaves, sweet cherry trees can be used for ornamental purpose and in association with ornamental plants in landscape design. The colourful leaves of this species make it suitable for landscape design by giving a great effect on the visual perception of the space.

\section{EXPERIMENTAL SECTION}

Plant material and sample preparation. Five varieties of sweet cherry tree were selected to be studied: Merchant, Early Red, Lapins, Burlat, Kordia. Leaves were collected in autumn of 2016 from Steluta Farm Ltd. 
orchard located in Cluj-Napoca, Romania. All five varieties were cultivated under full sun. The colour transformation of the leaves was observed during one month and the samples were collected in two steps: when the leaves turned on in yellow and after the leaves became red. In this way, the ornamental value of the cherry tree which is given by the leaves colour can be highlight. In order to identify the pigments content of the leaves, extraction and quantification of the carotenoids and anthocyanins were performed.

Chemicals. Methanol, ethyl acetate, petroleum ether, diethyl ether, sodium chloride, anhydrous sodium sulphate was purchased from Merck, Germany. Lutein, zeaxanthin and $\beta$-carotene standards were provided by LGC Standards. Methanol and tert-butyl methyl ether (TBME) (HPLC grade) were purchased from Merck.

Extraction of carotenoid pigments. Carotenoids were extracted from $5 \mathrm{~g}$ leaves using the procedure described by [44]. The leaves were homogenized and extracted three times with a mixture of methanol/ethyl acetate/petroleum ether $(1: 1: 1, \mathrm{v} / \mathrm{v} / \mathrm{v})$. The combined extracts were partitioned in a separatory funnel with water, diethyl ether and saline solution, the ether phase was evaporated to dryness. The extract rich in carotenoids was further diluted with TBME, filtered (PTFE, $0.45 \mu \mathrm{m}$ ) and subjected to high-performance liquid chromatography-photodiode array detector (HPLC-PDA) analysis.

HPLC Determination of carotenoid pigments. HPLC-PDA was performed using a Shimadzu system LC20 AT with a SPD-M20A diode array detector and YMC C30 column (24 cm x $4.6 \mathrm{~mm}$; particle size $5 \mu \mathrm{m})$ was used. The mobile phase used was a mixture of two solvents: solvent $A$ : methanol/tert-butyl methyl ether/water $(81: 15: 4, \mathrm{v} / \mathrm{v} / \mathrm{v})$ and solvent B: tertbutyl methyl ether/methanol/water $(90: 7: 3, \mathrm{v} / \mathrm{v} / \mathrm{v})$. The gradient started with $1 \% \mathrm{~B}$ at min 0 and increased to $100 \% \mathrm{~B}$ at min 160 according to the method described by [45]. The flow-rate was adjusted to $0.8 \mathrm{ml} \mathrm{min}^{-1}$. The carotenoids identification in leaves was carried out by comparison of the UV-VIS spectra and retention time of sample peaks with those of the standards [46]. The carotenoids concentration was calculated using calibration curves of carotenoid standards (lutein, zeaxanthin and beta-carotene).

Extraction of anthocyanin pigments. Anthocyanins were extracted from the leaves with acidified methanol $(0.3 \% \mathrm{HCl})$ using a homogenizer (Miccra D-9 KT Digitronic, Bergheim, Germany). Re-extraction was done until the residue was colourless, the final extraction was done overnight, at $4^{\circ} \mathrm{C}$ in the dark. The colored extract was filtered then concentrated under vacuum to remove methanol. After adding $1 \mathrm{ml}$ of methanol, filtered through $0.45 \mu \mathrm{m}$ the samples were analysed using HPLC-DAD. 
HPLC Determination of anthocyanin pigments. Analyses were performed on a Shimadzu HPLC system equipped with a binary pump delivery system LC-20 AT (Prominence), a degasser DGU-20 A3 (Prominence), diode-array SPD-M20 A UV-VIS detector and a Luna Phenomenex C-18 column $(5 \mu \mathrm{m}, 25 \mathrm{~cm} \times 4.6 \mathrm{~mm})$ was used. The mobile phase consisted in: solvent A-formic acid (4.5\%) in bidistilled water and solvent B - acetonitrile. The gradient elution system was: $10 \% \mathrm{~B}, 0-9 \mathrm{~min} ; 12 \% \mathrm{~B}, 9-17 \mathrm{~min} ; 25 \% \mathrm{~B}$ $17-30 \mathrm{~min} ; 90 \% \mathrm{~B}, 30-50 \mathrm{~min} ; 10 \% \mathrm{~B}, 50-55 \mathrm{~min}$. The flow rate was 0.8 $\mathrm{ml} / \mathrm{min}$ and the analyses were performed at $35^{\circ} \mathrm{C}$. The chromatograms were monitored at $520 \mathrm{~nm}$. The compounds identification and peak assignments were done based on their retention times, UV-VIS spectra and also comparing with standards (cyaniding-30-glucoside) and published data. The anthocyanin quantification was performed by using cyanidin-3-O-galactoside as pure standard and the calculation were made using calibration curve.

Statistical analysis. The extraction was made in triplicate from each leaves analysed. Values of each cultivar were averaged and standard deviations were calculated. Data obtained were statistically evaluated using analyse of variance (ANOVA) with Duncan test in order to compare means among groups and to determine significant differences among concentration of pigments in leaves. The level of significance used was $p<0.05$. Principal component analysis (PCA) was used to determine the correlations between pigments contain and Prunus avium L. studied cultivars.

\section{REFERENCES}

1. K. Yamazaki, Naturwissenschaften, 2008, 95, 671.

2. M. Archetti, Journal of Theoretical Biology, 2000, 205, 625.

3. W.D. Hamilton, S.P. Brown, Proc Roy Soc Lond B, 2001, 268, 1489.

4. D.W. Lee, K.S. Gould, Amer Sci, 2002, 90, 524.

5. Y. Manetas, Flora, 2006, 201, 163.

6. D.A. Sims, J.A. Gamon, Remote Sensing of Environment, 2002, 81, 337.

7. P. Matile, Exp Gerontol, 2000, 35,145.

8. M. Archetti, T.F. Doring, S.B. Hagen, N.M. Hughes, S.R. Leather, D.W. Lee, S. Lev-Yadun, Y. Manetas, H.J. Ougham, P.G. Schaberg, T. Howard, Trends in Ecology and Evolution, 2009, 24, 3.

9. M. Archetti, S.P. Brown, The Royal Society, Proc. R. Soc. Lond. B, 2004, 271, 1219. 
10. A.D. Webster, Crop physiology, production and uses, CAB International, Wallingford, Oxon, UK, 1996.

11. U. Szymanowska, U. Złotek, M. Karas, B. Baraniak, Food Chemistry, 2015, $172,71$.

12. L. Hai-Peng, D. Wei-Dong, T. Jun-Feng, G. Li, Z. Yin, L. Zhi, Journal of Functional Foods, 2015, 17, 449.

13. Y. Zhang, J. Zhang, T. Song, J. Li, J. Tian, K. Jin, PLoS ONE, 2014, 9, 6.

14. G.A. Blackburn, J. Exp. Bot., 2007, 58, 855.

15. S.C. Chae, S.W. Lee, J.K. Kim, W.T. Park, M.R. Uddin, H.H. Kim, S.U. Park, Asian Journal of Chemistry, 2013, 25, 8.

16. L. Taiz, E. Zeiger, Plant Physiology. Sinauer Associates Inc., 2002, Sunderland.

17. J. Keskitalo, G. Bergquist, P. Gardeström, S. Jansson, Plant Physiology, 2005, $139,4$.

18. R.J. McLain, M.R. Poe, P.T. Hurley, J. LeCompte, M.R. Emery, Urban Forestry \& Urban Greening, 2012, 11, 2.

19. E.D.G. Fraser, A.W. Kenney, Journal of Arboriculture, 2000, 26, 2.

20. S.R. Kumar, S.N. Prasad, P. Giridhar, Eur Food Res Technol, 2014, 238,971.

21. B.J. Glover, International Journal of Design \& Nature and Ecodynamics, 2009, $4,3$.

22. Y. Tanaka, N. Sasaki, A. Ohmiya, The Plant Journal: For Cell and Molecular Biology, 2008, 54, 4.

23. H. Zhang, M. Jordheimb, D.H. Lewisa, S. Arathoona, M.A. Øyvind, K.M. Davies, Scientia Horticulturae, 2014, 165, 29.

24. T. Goto, T. Kondo T, Angewandte Chemie International Edition, 1991, 30,1.

25. N.M. Karaaslan, M. Yaman, Eur Food Res Technol, 2015, doi: 10.1007/s00217015-2524-9.

26. N. Rim, S. Achour, M. Jourdes, P.L. Teissedre, A.N. Helal, B. Ezzili, J. Int. Sci. Vigne Vin, 2013, 47, 4.

27. S. Islam, M. Yoshimoto, N. Terahara, O. Yamakawa, Biosci. Biotechnol. Biochem., 2002, 66, 11, 2483.

28. C. Carrillo, C. Buvé, A. Panozzo, T. Grauwet, M. Hendrickx, Food Chemistry, 2017, 227, 271.

29. I. Sensoy, Critical Reviews in Food Science and Nutrition, 2014, 54, 7, 902.

30. B. Llorente, J.F. Martinez-Garcia, C. Stange, M. Rodriguez-Concepcion, Plant Biology, 2017, 37, 49.

31. T.S. Agostini-Costa, G.K.A. Pêssoa, D.B. Silva, I.S. Gomes, J.P. Silva, Journal of functional foods, 2014, 11, 178.

32. E. Murillo, A. Melendez-Martinez, F. Portugal, Food Chemistry, 2010, 122, 1, 167.

33. A.S. Gallinat, R.B. Primack, D.L. Wagner, Trends in Ecology \& Evolution, 2015, $30,3$.

34. G.A.E. Hendry, New Scientist, 1988, 1637, 38.

35. W.A. Hoch, E.L. Zeldin, B.H. McCown, Tree Physiology, 2001. 21, 1-8.

36. D.W. Lee, J. O'Keefe, N.M. Holbrook, T.S. Field, Ecological Research, 2003, 18,677 . 
37. J.K. Holopainen, P. Peltonen, Oikos, 2002, 99, 184.

38. T.C.W. Nijboer, R. Kanai, E.H.F De Haan. M.J. Van der Smagt, Consciousness and Cognition, 2007, 17, 741.

39. J. Gage," Colour and Culture: Practice and Meaning from Antiquity to Abstraction", Thames and Hudson, 1993, London.

40. M.J. Grose, Journal of the Royal Society of Western Australia, 2007, 90, 179.

41. G. Monge, Annales deChimie, 1789, 3, 131.

42. M. Lancaster," Colourscape", Academy Ed. London, 1996.

43. M.J. Grose, Landscape and Urban Planning, 2016, 146, 20.

44. J. Schlatterer, D.E. Breithaupt, J. Agr. Food Chem., 2006, 54, 2267.

45. D. Giuffrida, A. Pintea, P. Dugo, G. Torre, R.M. Pop, Mondello L., Phytochem Analysis, 2012, 23, 267.

46. G. Britton, S. Liaaen-Jensen, H. Pfander," Carotenoids", Birkhäuser, Basel, 1996, Vol.1B. 
